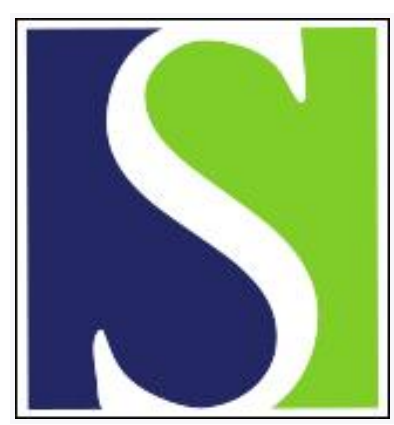

Scand J Work Environ Health 1988;14(5):299-305

https://doi.org/10.5271/sjweh.1916

Issue date: Oct 1988

Neck and shoulder symptoms among men in machine operating, dynamic physical work and sedentary work.

by Tola S, Riihimaki H, Videman T, Viikari-Juntura E, Hanninen K

Affiliation: Local Government Pension Institute, Helsinki, Finland.

This article in PubMed: www.ncbi.nlm.nih.gov/pubmed/3201189 


\title{
Neck and shoulder symptoms among men in machine operating, dynamic physical work and sedentary work
}

\author{
by Sakari Tola, MD, ${ }^{1}$ Hilkka Riihimäki, MD, MSc, ${ }^{2}$ Tapio Videman, $M D,{ }^{3}$ \\ Eira Viikari-Juntura, MD, ${ }^{3}$ Kari Hänninen, $\mathrm{MSc}(\text { Eng })^{2}$
}

\begin{abstract}
TOLA S, RIIHIMÄKI H, VIDEMAN T, VIIKARI-JUNTURA E, HÄNNINEN K. Neck and shoulder symptoms among men in machine operating, dynamic physical work and sedentary work. Scand $J$ Work Environ Health 14 (1988) 299-305. Data on the occurrence of neck and shoulder symptoms and some qualities of work and leisure-time activities were gathered with a postal questionnaire sent to 1174 machine operators, 1045 carpenters, and 1013 office workers. They were all men in the age range of $25-49$ years. The response rate was $67-76 \%$. The lifetime cumulative incidence of neck and shoulder symptoms was $81 \%$ for the machine operators, $73 \%$ for the carpenters, and $57 \%$ for the office workers. About half of the two groups of manual workers and $24 \%$ of the office workers had had symptoms during the last $7 \mathrm{~d}$. Pain in the arms was indicated by $14-17 \%$ of the manual workers and $4 \%$ of the office workers. Symptoms during more than $30 \mathrm{~d}$ within the last 12 months were also more common among the manual workers than among the office workers. Within the manual worker groups, the machine operators had more symptoms than the carpenters. In a multivariate logistic regression analysis occupation, working in twisted or bent postures, age, draft, and job satisfaction proved to be significant risk indicators for neck and shoulder symptoms.
\end{abstract}

Key terms: cervicobrachial symptoms, cross-sectional study, epidemiology, occupation, questionnaire study, work postures.

Neck and shoulder symptoms belong to those musculoskeletal disorders that are often difficult to diagnose specifically in clinical studies. In epidemiologic surveys their concept is even vaguer. Nevertheless, it seems that different occupational risk factors have an important role in aggravating or - at least to some extent - causing these disorders $(1,3,7,11)$. Even though a generally accepted and clinically applicable diagnostic classification does not seem easy to achieve, the identification of risk factors of even ill-defined disorders in occupational health practice may help prevent these symptoms.

In the present questionnaire study we have primarily aimed at determining the frequency of neck and shoulder symptoms among male workers who represent three types of work load, ie, (i) machine operating, (ii) dynamic physical work, and (iii) sedentary work. We also attempted to identify the risk factors associated with these disorders.

The results of this questionnaire study will serve as a base line for a prospective study.

\section{Subjects and methods}

Because of the selection of the older age groups out of work on one hand and the low prevalence of neck

1 Local Government Pension Institute, Helsinki, Finland.

2 LEL Employment Pension Fund, Helsinki, Finland.

3 Institute of Occupational Health, Helsinki, Finland.

Reprint requests to: Dr S Tola, Eläke-Varma, Annankatu 18 A, 00120 Helsinki, Finland. and shoulder disorders among younger age groups on the other, the study was restricted to men aged $25-49$ years.

In machine operating, workers are exposed to lowfrequency whole-body vibration and to static load due to prolonged sitting and the handling of steering apparatus. Machine operators' work also includes occasional materials handling and maintenance of the machine. The occupations selected to represent machine operators were earthmover operators and longshoremen specialized in motorized stevedoring. The most common machine used by longshoremen is the fork-lift truck. The surface on which it is operated is usually smooth, but there are often obstacles. In the loading and unloading of ships, the work pace is fast, and machines have to be operated in cramped spaces that often allow only back and forth movements without turns. This situation forces operators to rotate the upper trunk to attain visibility while backing up. Earthmover operators mostly use heavier machinery, such as excavators, bulldozers, loaders, etc, in preparing the ground for buildings and in road construction. The surfaces are rough, but the machines often move rather slowly, and there is less need to back up than in stevedoring.

The longshoremen $(\mathrm{N}=764)$ and the earthmover operators $(\mathrm{N}=410)$ were identified in the employers' registers, and all the men fulfilling the age criteria were included. In spite of the differences in the environment and equipment of the two groups, the prevalence of neck and shoulder symptoms did not differ significant- 
ly between the two, and therefore the groups were combined.

Carpenters were selected to represent dynamic physical work. They were skilled construction workers whose task was to build molds and other structures made of wood, ie, walls, roofs, floors, etc. A carpenter's work is mainly dynamic muscular work with varying postures and loads, but it also includes tasks causing static loading of, especially, the neck-shoulder-arm region. The loads handled are usually not excessively heavy. The carpenters were identified from the trade union's registers, and, in order to have a comparable geographic distribution, a stratified sample of 1045 men was drawn.

Municipal office workers were selected to represent sedentary workers. An attempt was made to find a group of male sedentary workers with the same socioeconomic status as the two other groups, but it was impossible. The office workers $(\mathrm{N}=1013)$ were selected from the employers' registers of the same towns as the other groups. All nonexecutive male of fice workers fulfilling the age criteria were selected with the exception of those in the two largest cities (Helsinki and Turku), among whom only every other man was chosen. According to the questionnaire, only about $40 \%$ of the sample was estimated to perform routine office tasks, such as typing or using visual display units for longer periods. It seems that this group had less typical loading factors of office work than a group of female office workers would have had.

The postal questionnaire included 52 questions concerning education, work history, loading factors at work, general health, and leisure-time physical activities. The questions on neck and shoulder symptoms

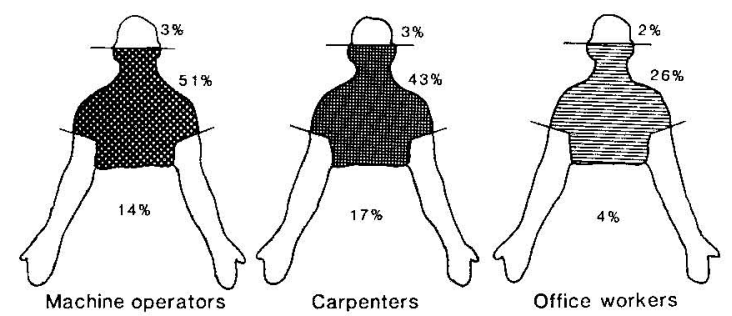

Figure 1. The pain drawing showing pain during the past $7 \mathrm{~d}$. were the following.

1. Have you ever had symptoms in the neck or shoulders?
1. No
2. Yes

2. Have you sometimes had to change work or work methods because of symptoms of the neck or shoulders?

1. No

2. Yes

3. Estimate the number of days within the last 12 months during which you have had symptoms of the neck or shoulders.
1. None
2. 1-7 days
3. $8-30$ days
4. More than 30 days but not daily
5. Daily

4. Estimate the number of days within the last 12 months during which you have been unable to perform your daily duties (at your workplace, home, etc) because of symptoms of the neck or shoulders.
1. None
2. $1-7$ days
3. $8-30$ days
4. More than 30 days

5. Have you diminished or changed your daily activities or leisure-time hobbies because of symptoms of the neck or shoulders within the last 12 months?

1. No

2. Yes

6. How have your neck and shoulders been within the last seven days?

1. My neck and shoulders have been well and I have had no symptoms

2. I have had symptoms of the neck or shoulders, but I have been able to perform most of my daily tasks (at my workplace, home, etc)

3. I have symptoms of the neck or shoulders that have limited my performance of most of my

Table 1. Age distribution of the occupational groups.

\begin{tabular}{|c|c|c|c|c|c|c|}
\hline \multirow{2}{*}{ Age (years) } & \multicolumn{2}{|c|}{ Machine operators } & \multicolumn{2}{|c|}{ Carpenters } & \multicolumn{2}{|c|}{ Office workers } \\
\hline & $N$ & $\%$ & $\mathrm{~N}$ & $\%$ & $\mathrm{~N}$ & $\%$ \\
\hline $25-29$ & 157 & 18.4 & 80 & 11.5 & 53 & 7.9 \\
\hline $30-34$ & 145 & 17.0 & 160 & 23.0 & 138 & 20.5 \\
\hline $35-39$ & 192 & 22.5 & 152 & 21.9 & 212 & 31.4 \\
\hline $40-44$ & 195 & 22.9 & 145 & 20.8 & 162 & 24.0 \\
\hline $45-49$ & 163 & 19.1 & 159 & 22.8 & 109 & 16.2 \\
\hline Total & 852 & 100.0 & 696 & 100.0 & 674 & 100.0 \\
\hline
\end{tabular}


daily tasks or I have been unable to work for at least one day

The respondents were also asked to indicate, on a pain drawing (9), areas where they had felt pain during the past $7 \mathrm{~d}$. We analyzed these pain drawings using a grid which separated most of the head and upper extremities from the upper body (figure 1). Markings in each area were recorded, but the number of markings was not analyzed separately.

The question regarding twisted or bent postures during work was the following:

On the average, how much do you work in a bent or twisted posture?

1. Very little

2. Rather little

3. Moderately

4. Rather much

5. Very much

Two reminders were sent to those who did not reply. The final response rate was $74 \%$ for the machine operators, $67 \%$ for the carpenters, and $67 \%$ for the office workers. The age distribution of the respondents and nonrespondents was similar in all three occupational groups.

The mean ages of the machine operators (37.3 years), the carpenters (38.1 years), and the office workers ( 38.0 years) were similar, but there were some differences in the groups' age distributions (table 1). The youngest age group (25-29 years) was underrepresented among the office workers as compared with the other groups $(7.9 \%$ versus $18.4 \%$ of the machine operators and $11.5 \%$ of the carpenters).

Risk ratio estimates and their $95 \%$ confidence intervals were calculated as measures of effect. To control for confounding by age, the Mantel-Haenszel procedure for stratified data was used. To analyze further the effect of several covariates showing a significant univariate relation to the occurrence of neck and shoulder symptoms, multivariate logistic regression modeling was employed. Calculations were made with the GLIM3 program (2) along with a macro, presented by Wacholder (10), which allows the estimation of risk ratios and their $95 \%$ confidence intervals from regression coefficients and their standard errors. The dependent variable was the 12 -month prevalence of neck and shoulder symptoms on eight or more days. The predictor variables were occupational exposure (office workers, carpenters, machine operators), age (five-year classes), reported use of twisted or bent postures during work (four classes), complaint of draft (no, yes), and job satisfaction (three classes). The possible effect of the duration of exposure, as measured by the years in current occupation, was also analyzed, but, after inclusion of age in the model, its effect was nonsignificant. Thus only occupation was used as the indicator of exposure. All predictor variables (represented by indicator variates) were introduced into the model simultaneously as main effect terms, after which we tested their significance by excluding them one at a time from the model and observing the change in the fit of the model. Significant interaction terms were also searched for, but none were detected.
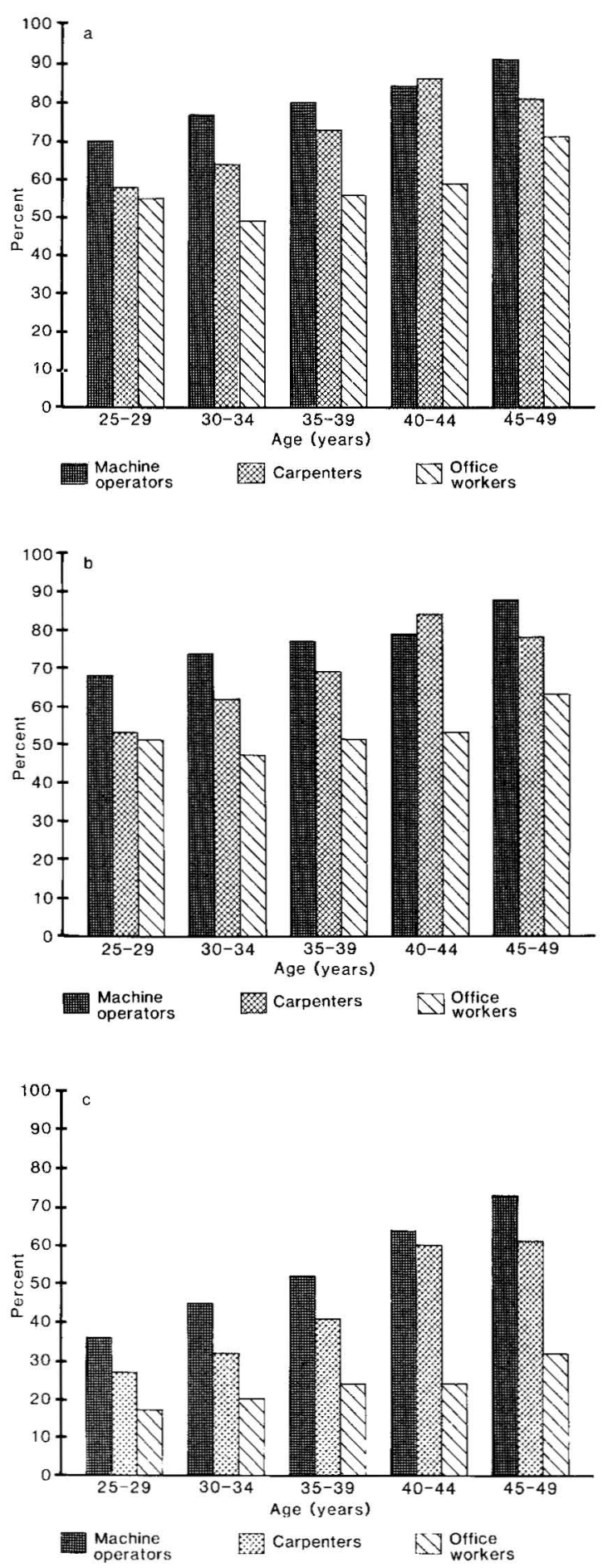

Figure 2. Neck and shoulder symptoms ever (a), during the last 12 months (b), and during the last $7 \mathrm{~d}$ (c). 


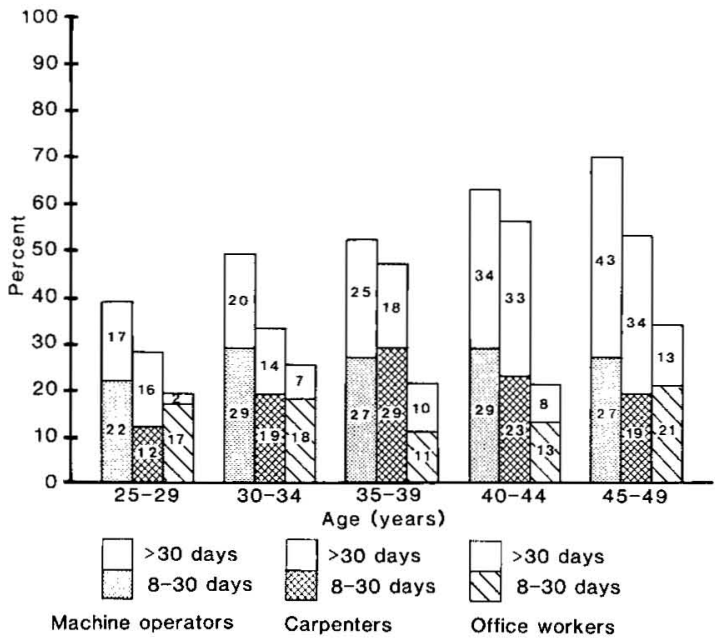

Figure 3. Persistency of neck and shoulder symptoms within the last 12 months.

\section{Results}

\section{Occurrence of neck and shoulder symptoms}

The lifetime cumulative incidence of neck and shoulder symptoms was high in all the occupational groups; it ranged from $81 \%$ among the machine operators to $73 \%$ among the carpenters and $57 \%$ among the office workers (figure 2a). The lifetime cumulative incidence was not much higher than the 12-month prevalence (figure 2b). About half of the manual workers had had symptoms during the last $7 \mathrm{~d}$ as compared with $24 \%$ of the office workers (figure 2c). A similar difference was detected also in the pain drawings (figure 1) with regard to pain somewhere in the neck, shoulder, and posterior thoracic region during the last $7 \mathrm{~d}$. Pain in the arms was indicated by $14-17 \%$ of the manual workers and only $4 \%$ of the office workers.

Symptoms during more than $30 \mathrm{~d}$ within the past 12 months were more common among the manual than the office workers (figure 3). Daily symptoms were

Table 2. Percentage of workers with neck and shoulder symptoms within a certain educational group during the last 12 months according to bccupation. (NS = not significant)

\begin{tabular}{|c|c|c|c|}
\hline \multirow[b]{2}{*}{ Occupation } & \multicolumn{2}{|c|}{ Education } & \multirow{2}{*}{$\begin{array}{c}\text { Statistical } \\
\text { significance }\end{array}$} \\
\hline & $\begin{array}{l}\text { No more than } \\
\text { some courses }^{\mathrm{a}}\end{array}$ & $\begin{array}{c}\text { At least } \\
\text { vocational school }\end{array}$ & \\
\hline $\begin{array}{l}\text { Machine operators } \\
\text { Carpenters } \\
\text { Office workers }\end{array}$ & $\begin{array}{ll}79 & (\mathrm{~N}=603) \\
74 & (\mathrm{~N}=388) \\
50 & (\mathrm{~N}=34)\end{array}$ & $\begin{array}{ll}72 & (N=212) \\
65 & (N=283) \\
53 & (N=633)\end{array}$ & $\begin{array}{c}\mathrm{P}<0.05 \\
\mathrm{P}<0.01 \\
\mathrm{NS}\end{array}$ \\
\hline
\end{tabular}

a $\mathbf{N}=$ number of workers in the group.

Table 3. Distribution of the workers according to the number of days with neck and shoulder symptoms within the last 12 months, occupation, and the use of twisted or bent postures during work.

\begin{tabular}{|c|c|c|c|c|c|c|c|c|c|c|}
\hline \multirow{3}{*}{$\begin{array}{l}\text { Use of twisted or } \\
\text { bent postures at work }\end{array}$} & \multicolumn{10}{|c|}{ Days with neck and shoulder symptoms within the last 12 months } \\
\hline & \multicolumn{2}{|c|}{ None } & \multicolumn{2}{|c|}{$1-7 d$} & \multicolumn{2}{|c|}{$8-30 \mathrm{~d}$} & \multicolumn{2}{|c|}{$\begin{array}{l}\text { More than } \\
30 \mathrm{~d} \text { or daily }\end{array}$} & \multicolumn{2}{|c|}{ Total } \\
\hline & $\mathbf{N}$ & $\%$ & $\mathrm{~N}$ & $\%$ & $\mathrm{~N}$ & $\%$ & $\mathrm{~N}$ & $\%$ & $\mathrm{~N}$ & $\%$ \\
\hline \multicolumn{11}{|l|}{ Machine operators } \\
\hline $\begin{array}{l}\text { Rather or very little } \\
\text { Moderately } \\
\text { Rather much } \\
\text { Very much }\end{array}$ & $\begin{array}{l}52 \\
39 \\
59 \\
37\end{array}$ & $\begin{array}{l}32.5 \\
27.9 \\
20.6 \\
15.3\end{array}$ & $\begin{array}{l}49 \\
41 \\
57 \\
40\end{array}$ & $\begin{array}{l}30.6 \\
29.3 \\
19.9 \\
16.5\end{array}$ & $\begin{array}{l}36 \\
38 \\
92 \\
53\end{array}$ & $\begin{array}{l}22.5 \\
27.1 \\
32.2 \\
21.9\end{array}$ & $\begin{array}{r}23 \\
22 \\
78 \\
112\end{array}$ & $\begin{array}{l}14.4 \\
15.7 \\
27.3 \\
46.3\end{array}$ & $\begin{array}{l}160 \\
140 \\
286 \\
242\end{array}$ & $\begin{array}{l}100.0 \\
100.0 \\
100.0 \\
100.0\end{array}$ \\
\hline Total & 187 & 22.6 & 187 & 22.6 & 219 & 26.4 & 235 & 28.4 & 828 & 100.0 \\
\hline \multicolumn{11}{|l|}{ Carpenters } \\
\hline $\begin{array}{l}\text { Rather or very little } \\
\text { Moderately } \\
\text { Rather much } \\
\text { Very much }\end{array}$ & $\begin{array}{r}6 \\
40 \\
86 \\
62\end{array}$ & $\begin{array}{l}31.6 \\
44.0 \\
29.7 \\
24.0\end{array}$ & $\begin{array}{r}7 \\
26 \\
83 \\
56\end{array}$ & $\begin{array}{l}36.8 \\
28.6 \\
28.6 \\
21.7\end{array}$ & $\begin{array}{r}1 \\
11 \\
71 \\
54\end{array}$ & $\begin{array}{r}5.3 \\
12.1 \\
24.5 \\
20.9\end{array}$ & $\begin{array}{r}5 \\
14 \\
50 \\
86\end{array}$ & $\begin{array}{l}26.3 \\
15.4 \\
17.2 \\
33.3\end{array}$ & $\begin{array}{r}19 \\
91 \\
290 \\
258\end{array}$ & $\begin{array}{l}100.0 \\
100.0 \\
100.0 \\
100.0\end{array}$ \\
\hline Total & 194 & 29.5 & 172 & 26.2 & 137 & 20.8 & 155 & 23.6 & 658 & 100.0 \\
\hline \multicolumn{11}{|l|}{ Office workers } \\
\hline $\begin{array}{l}\text { Rather or very little } \\
\text { Moderately } \\
\text { Rather much } \\
\text { Very much }\end{array}$ & $\begin{array}{r}195 \\
50 \\
54 \\
16\end{array}$ & $\begin{array}{l}56.2 \\
47.6 \\
34.8 \\
32.0\end{array}$ & $\begin{array}{l}94 \\
29 \\
47 \\
14\end{array}$ & $\begin{array}{l}27.1 \\
27.6 \\
30.3 \\
28.0\end{array}$ & $\begin{array}{l}40 \\
19 \\
32 \\
12\end{array}$ & $\begin{array}{l}11.5 \\
18.1 \\
20.7 \\
24.0\end{array}$ & $\begin{array}{r}18 \\
7 \\
22 \\
8\end{array}$ & $\begin{array}{r}5.2 \\
6.7 \\
14.2 \\
16.0\end{array}$ & $\begin{array}{r}347 \\
105 \\
155 \\
50\end{array}$ & $\begin{array}{l}100.0 \\
100.0 \\
100.0 \\
100.0\end{array}$ \\
\hline Total & 315 & 48.0 & 184 & 28.0 & 103 & 15.7 & 55 & 8.4 & 657 & 100.0 \\
\hline
\end{tabular}


complained of by $11 \%$ of the machine operators, $8 \%$ of the carpenters, and $2 \%$ of the office workers. Within the manual worker groups the carpenters had, in general, somewhat fewer symptoms than the machine operators, and the difference was statistically significant for the symptoms during the last $7 \mathrm{~d}$ and for the more persisting symptoms (figures $2 \mathrm{c}$ and 3 ).

The symptoms had caused more trouble for the manual workers than for the office workers. Nineteen percent of the machine operators, $21 \%$ of the carpenters, and $10 \%$ of the office workers had sometimes changed work or work methods because of the symptoms. A decrease or change in daily activities or leisuretime hobbies because of neck and shoulder pain was reported by $14 \%$ of the machine operators, $13 \%$ of the carpenters, and $9 \%$ of the office workers.

\section{Risk indicators}

There was some indication of an association between education and the symptoms. The office workers had fewer symptoms than the other groups, but higher education was associated with fewer symptoms to some extent also among the machine operators and carpenters (table 2).

No association was found between the symptoms and car driving in any of the occupational groups.

Working in twisted or bent postures increased the occurrence of neck and shoulder symptoms, and this association was the most evident for the machine operators (table 3 ).

The univariate relations of occupational exposure and the covariates included in the multivariate analysis are presented in tables 4 and 5 . In the multivariate analysis all the variates proved to have a significant effect on the 12-month prevalence of neck and shoulder symptoms (table 6). There was a notable confounding effect by the covariates on the effect of occupational exposure, except for the contrast between machine operators and carpenters. Machine operating, working in twisted or bent postures, and age were the most powerful predictors for neck and shoulder symptoms.

\section{Discussion}

Neck and shoulder symptoms were common among all the occupational groups studied. The manual workers had more symptoms than the office workers, but there was also a clear difference in the prevalence of symptoms among the manual workers, machine operators having more symptoms than the carpenters. In addition to occupation, twisting and bending during work and age were strong risk indicators. Job satisfaction and draft also showed some association with the symptoms.

The validity of information in this questionnaire study seems comparable to that of similar studies. The
Table 4. Relative risks (RR) with their $95 \%$ confidence intervals (in parentheses) for the effect of occupational exposure on the occurrence of neck and shoulder symptoms on eight or more days during the past 12 months.

\begin{tabular}{|c|c|c|c|c|}
\hline \multirow{2}{*}{$\begin{array}{l}\text { Machine operators } \\
\text { versus office } \\
\text { workers }\end{array}$} & \multicolumn{2}{|c|}{ Crude RR } & \multicolumn{2}{|c|}{ Age-adjusted RR } \\
\hline & 2.3 & $(2.0-2.6)$ & 2.4 & $(2.1-2.7)$ \\
\hline $\begin{array}{l}\text { Carpenters versus } \\
\text { office workers }\end{array}$ & 1.8 & $(1.8-1.9)$ & 1.9 & $(1.6-2.2)$ \\
\hline $\begin{array}{l}\text { Machine operators } \\
\text { versus carpenters }\end{array}$ & 1.2 & $(1.1-1.4)$ & 1.9 & $(1.1-1.4)$ \\
\hline
\end{tabular}

Table 5. Univariate associations between covariates and the occurrence of neck and shoulder symptoms on eight or more days during the past 12 months.

\begin{tabular}{lcc}
\hline Covariate & $\begin{array}{c}\text { Relative } \\
\text { risk }\end{array}$ & $\begin{array}{c}95 \% \\
\text { confidence } \\
\text { interval }\end{array}$ \\
\hline $\begin{array}{l}\text { Job satisfaction } \\
\text { Very good } \\
\text { Moderate or poor }\end{array}$ & 1.0 &. \\
$\begin{array}{l}\text { Draft } \\
\text { No } \\
\text { Yes }\end{array}$ & 1.5 & $1.3-1.7$ \\
$\begin{array}{l}\text { Twisted or bent } \\
\text { postures at work } \\
\text { Rather or very little } \\
\text { Very much }\end{array}$ & 1.0 &. \\
\hline
\end{tabular}

Table 6. Risk ratios (RR) and their $95 \%$ confidence intervals $(95 \% \mathrm{Cl})$ for the adjusted effects of five risk indicators on the 12-month prevalence of neck and shoulder symptoms.

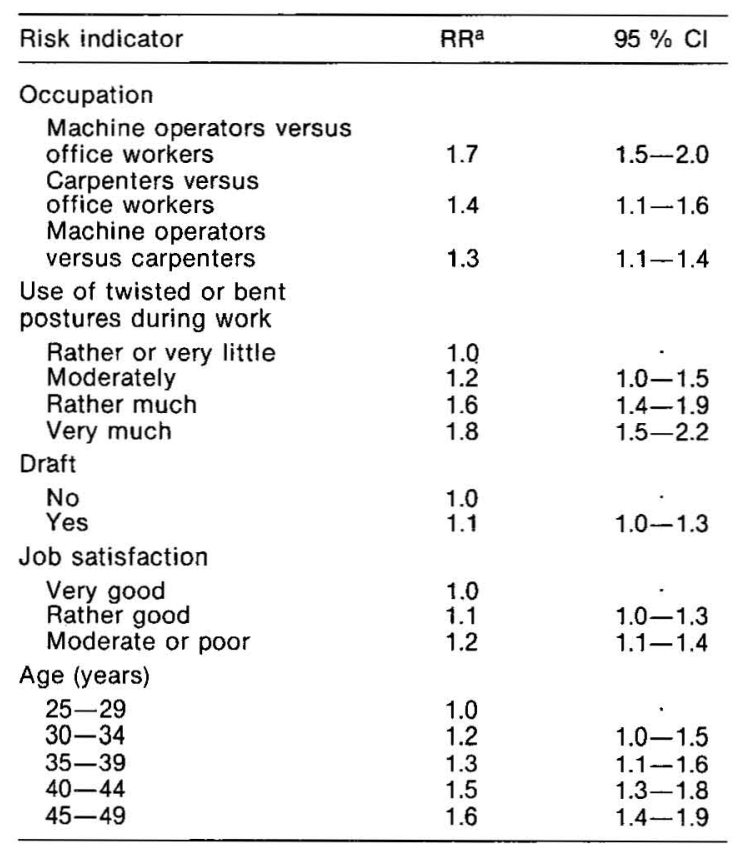

a Adjusted for all other covariates. 
questions and the pain drawing gave similar prevalences, and, in general, the answers were logical, ie, symptoms "ever" were more common than symptoms for a shorter and more defined period and long-lasting or disabling symptoms were less common. Hence it seems that the questions had been understood by the respondents. Since the response rate was also acceptable, the analysis should give meaningful information on the relationship between the occurrence of neck and shoulder symptoms and the studied risk indicators within the study itself.

The comparison with other studies is more difficult because of the inherent problems of the questionnaire technique in connection with musculoskeletal diseases. The rates found in this study were high but not exceptionally high as compared with those of similar studies (3). Because the way of asking about symptoms and cultural differences affect the answers, it is not meaningful to compare the exact percentages in various studies. It is more important to evaluate whether similar patterns emerge. Neck and shoulder symptoms have been evaluated with respect to the heaviness of the work and exposure to vibration in several crosssectional studies. The results are conflicting. In some studies individuals with physically demanding jobs have displayed a higher frequency of neck and shoulder symptoms $(5,11,12)$, but not in other studies $(6$, 8). In a study of earthmover operators and a reference group not exposed to whole-body vibration, neck pain was more common among the referents (4). Factors such as the classification of jobs and differences in the possibility to change occupation may account for the different results in the cross-sectional studies. The low prevalence of symptoms among the office workers in this study can probably be explained by the fact that the office workers were men and by the nonroutine type of office work performed by most of the respondents.

Exposure was defined as occupation. Consequently, these data were independent of the responses in the questionnaires. The data on symptoms, work postures, and other risk indicators were based on subjective evaluation. Those persons with symptoms may be more likely to perceive and report things which could be connected with the symptoms. Therefore, the associations of symptoms with risk indicators other than occupation should be assessed with caution.

The present findings should reflect the rate of neck and shoulder symptoms in different homogeneous occupational groups in a comparable way. Neck and shoulder symptoms were more common in the manual worker groups than among the office workers. This comparison is hampered by several possibilities of bias caused by the different educational level and social background of these worker groups. The effect of this kind of bias on the comparison between the machine operators and carpenters should be small. It is interesting that the machine operators, representing more static and torsional load, had more symptoms than the carpenters, who had dynamic and occasional high peak loading. The risk ratio between the machine operators and the carpenters did not change when other identified risk indicators were controlled in the multivariate analysis. This finding suggests that some unidentified loading factors, possibly vibration and static load, could be responsible for the excess prevalence of neck and shoulder symptoms among the machine operators. The fact that there was a difference between the manual worker groups strongly suggests that work postures may precipitate or aggravate neck and shoulder symptoms.

The assumption that the differences found between the occupational groups were, at least to some extent, caused by occupational factors is also supported by the results of the multivariate analysis, which clearly showed that self-reported twisted or bent postures during work were associated with an increased prevalence of neck and shoulder symptoms. The twisted or bent postures displayed the highest risk ratios, and also biomechanically this association was expected. Such vague concepts as draft and job satisfaction were also associated with neck and shoulder symptoms. The possible reason for these associations is more difficult to understand, but at least in the manual worker groups occupational loading factors may be involved since the social background of these groups was similar.

The cross-sectional nature of the present study limits the possibilities for assessing the causal effect of the identified risk factors, and a follow-up study is in progress.

\section{References}

1. Anderson JAD. Shoulder pain and tension neck and their relation to work. Scand J Work Environ Health 10 (1984) 435-442.

2. Baker RJ, Nelder JA. The GLIM system - Release 3, general linear interactive modelling. Numerical Algorithms Group, Oxford 1978.

3. Hagberg M, Wegman DH. Prevalence rates and odds ratios of shoulder-neck diseases in different occupational groups. Br J Ind Med 44 (1987) 602-610.

4. Hilfert R, Köhne G, Toussaint R, Zerlett G. Probleme der Gantzkörperschwingungsbelastung von Erdbau Maschinen Führern. Zentralbl Arbeitsmed Arbeitssch 31 (1981) 199-206.

5. Hult L. The Munkfors investigation. Acta Orthop Scand (1954): suppl 16, $76 \mathrm{p}$.

6. Hult L. Cervical, dorsal and lumbar spinal syndromes. Acta Orthop Scand (1954): suppl 17, 102 p.

7. Kvarnström, S. Occurrence of musculoskeletal disorders in a manufacturing industry, with special attention to occupational shoulder disorders. Scand J Rehabil Med (1983): suppl 8, $114 \mathrm{p}$.

8. Partridge REH, Duthie JJR. Rheumatism in dockers and civil servants: A comparison of heavy manual and sedentary workers. Ann Rheum Dis 27 (1968) 559-568.

9. Ransford AO, Cairns D, Mooney V. The pain drawing as an aid to the psychologic evaluation of patients with low back pain. Spine 1 (1976) 127-134.

10. Wacholder S. Binomial regression in GLIM: Estimating risk ratios and risk differences. Am J Epidemiol 123 (1986) $174-184$. 
11. Waris P. Occupational cervicobrachial syndromes: A review. Scand J Work Environ Health 5 (1979): suppl $3,3-14$.

12. Westerling $\mathrm{D}$, Jonsson BG. Pain in the neck-shoulder region and sick leave. Scand J Soc Med 8 (1980) $131-136$

Received for publication: 15 February 1988 